\title{
Die Kohlehydratverbrennung in den Muskeln und ihre Beeinflussung durch das Pankreas.
}

\author{
(I. Mitteilung.) \\ Von \\ Otto Cohnheim.
}

(Aus dem physiologischen Institut Heidelberg.)

(Der Redaktion zugegangen am 1. August 1903.)

In den Muskeln werden große Mengen von Traubenzucker verbrannt, und nach unseren heutigen Anschauungen ist anzunehmen, daß diese Verbrennung durch ein in den Muskeln enthaltenes Ferment geschieht. Ist doch die Spaltung des Traubenzuckers in der Hefe von Buchner ${ }^{1}$ ) auf ein Ferment, die Zymase, zurückgeführt worden, und haben $\mathrm{Hahn}^{2}$ ) und Stoklasa ${ }^{3}$ ) gezeigt, daß auch die höheren Pflanzen ein derartiges Enzym enthalten. Es hat indessen bisher nur Lauder Brunton ${ }^{4}$ ) ein äußerst schwaches glykolytisches Ferment in den Muskeln beschrieben. Sonst ist immer nur von der Glykolyse

1) E. Buchner, Alkoholische Gärung ohne Hefezellen. B. B. 30, 117, 1897. - 30,1110. - 31, 568, 1898. - E. Buchner u. R. Rapp, ibid. 30, 2668. - 31, 1084, 1090, 1531, 1898. - 32, 127 u. 2086, 1899. - R. Albert, B. B. 32, 2372, 1899. - R. Albert u. E. Buchner ibid. 33, 266, 1900. - E. Bu chner, 33, 3307, 3311. - R. Albert, E. Buchner u. E. Rapp, 35, 2376, 1902. - E. Buchner, H. Buchner u. M. Hahn, Zymasegärung, 1903.

2) M. Hahn, Chemische Vorgänge im zellfreien Gewebssaft von Arum maculatum. B. B. 33, 35̌55, 1900.

$\left.{ }^{3}\right)$ J. Stoklasa, J. Jelinek u. J. Vitek, Hofmeisters Beiträge 3, 460, 1903.

$\left.{ }^{4}\right)$ Lauder Brunton, On a probable glycolytic ferment in muscle etc. Zeitschr. f. Biologie 34, 487 (1896). - Lauder Brunton u. J. H. Rhodes, Zentralblatt f. Physiologie 12, 353, 1898. 
im Blute die Rede gewesen, die hauptsächlich von Lépine ${ }^{1}$ ) untersucht worden ist. Wie Krau s ${ }^{2}$ ) und Arthus ${ }^{3}$ ) ausführten, ist sie aber viel zu klein, als daß man sie für die Umsetzung von mehreren Hundert Gramm Dextrose im Organismus des Menschen verantwortlich machen könnte. In den Leukocyten, in denen Trümmer aller anderen Körperenzyme vorkommen, sind eben auch geringe Spuren des anderswo im Körper wirkenden glykolytischen Enzyms enthalten. ${ }^{4}$ )

Andererseits hat die Entdeckung des Pankreasdiabetes durch v. Mering und Minkowski ${ }^{5}$ ) gezeigt, daß das Pankreas der höheren Tiere eine entschejdende Rolle im Zuckerstoffwechsel spielt. Es secerniert ins Blut etwas, dessen Fehlen die Verbrennung des Traubenzuckers unmöglich macht, so wie sie unter pathologischen Bedingungen beim menschlichen Diabetes aufgehoben oder beschränkt ist. Es ist daher auch im Pankreas nach einem glykolytischen Ferment gesucht worden, indessen ohne Erfolg. ${ }^{6}$ ) Der einzige, der eine Zuckerzerstörung durch Pankreas in vitro beobachtet haben will, ist Šimáček, ?) und er hat unterdessen zugeben müssen, daß die Glykolyse in seinen Versuchen im wesentlichen durch Bakterien hervorgerufen worden war. ${ }^{8}$ ) Ich komme auf die Arbeit zurück.

Ich habe nun versucht, die beiden Organe zu kombinieren, und nachgesehen, ob vielleicht Muskel und Pankreas zusammen ein glykolytisches Ferment enthielten, das ihnen beiden getrennt abgeht. Es hat sich herausgestellt, daß dies in der Tat so ist.

1) R. Lépine, G. r. 110, 742, 1314, 1890. - R. Lépine u. Barral, Ferment glycolytique et Diabète, Paris 1891. - Dieselben, C. r. 112, 411, 604, 1185, 1414, 1891. - 113, 118, 729 u. 1014, 1891.

2) F. Krauss, Zeitschr. f. klin. Med. 21, 315, 1892.

8) M. Arthus, Arch. de Physiol. 24, 337 (nach Maly 23, 189), 1893.

4) M. Arthus, C. r. 114, 605, 1892. - Mém. Soc. Biol. 43, 65 (nach Maly 21, 99), 1891.

5) J. v. Mering u. O. Minkowski, Schmiedebergs Archiv f. experimentelle Pathologie u. Pharmakologie 26, 371, 1890. - 0. Minkow ski, ibid. 31, 85, 1893.

$\left.{ }^{6}\right)$ M. Herzog, Hofmeisters Beiträge II, 102, 1902.

7) E. Šimáč e k, Zentralbl. f. Physiologie 17, 3, 1903.

$\left.{ }^{8}\right)$ Derselbe, ibid. 17, 209, 1903. 
Aus dem Gemenge von Muskel und Pankreas läßt sich eine zellfreie Flüssigkeit gewinnen, die zugesetzten Traubenzucker so verändert, daß er nicht mehr durch die Reduktion nachgewiesen werden kann, während die vereinzelten Organe dies nicht tun.

Die erste und hauptsächlichste Schwierigkeit bei den Versuchen bestand in der genügenden Zerkleinerung der Muskeln. Die elastischen Sarkolemmschläuche, in denen das Plasma enthalten ist, lassen sich mittels einer Fleischhackmaschine garnicht, mit dem Wiegemesser schlecht zerkleinern, und durch Quarzsand noch viel schwerer zerreiben, als die Hefezellen in Buchners Versuchen. Ich kam nur durch Verwendung der von Kossel ${ }^{1}$ ) erfundenen Zerschneidemaschine zum Ziel. Bei ihr wird das Organ in einem Metallzylinder durch feste Kohlensäure zu Eis gefroren, und der Eiszylinder durch rotierende Messer abgefräst, in eine schneeartige Masse verwandelt. Die Zerkleinerung der Organe ist eine so vollkommene, daß man mikroskopisch in dem erhaltenen Brei nichts mehr von der charakteristischen Zellstruktur erkennen kann. Der Brei wird dann, genau wie in Buchners Versuchen, mit Kieselgur gemengt, in ein Koliertuch eingeschlagen und in einer hydraulischen Presse bei einem bis zu 300 Atmosphären gesteigerten Druck ausgepreßt. Anfangs setzte ich dem Muskelbrei *Ringersche Lösung z $z u$, d. h. physiologische Kochsalzlösung, die außer ClNa noch $\mathrm{CO}_{3} \mathrm{NaH}, \mathrm{ClK}$ und $\mathrm{Cl}_{2} \mathrm{Ca}$ enthält. Doch habe ich in mehreren Versuchen, in denen ich gerade viel Flüssigkeit zusetzte, sehr schlechte Resultate gehabt. Konstant war dies nicht, und es sind unten noch einige dieser Versuche mit aufgeführt; ich habe dann späterhin vorgezogen, jeden Zusatz zu unterlassen. Erst seit dieser Zeit wurden die Ergebnisse konstant.

Ich erhielt so aus frischen Hunde- oder Katzenmuskeln eine klare, je nach dem Blut- und Hämoglobingehalt mehr oder weniger rot gefärbte Flüssigkeit vom spezifischen Gewicht 1015-1020. $100 \mathrm{~g}$ Muskel lieferten bis zu $60 \mathrm{ccm}$ Flüssig-

1) A. Kossel, Diese Zeitschr., Bd. XXXIII, S. 5, 1901. 
keit. Die alte Kühnesche $\left.{ }^{1}\right)$ Anschauung, daß der eigentlich kontraktile Teil des Muskels, das Sarkoplasma, im lebenden Zustande eine Flüssigkeit ist, findet hierdurch eine schöne Illustration. Das erhaltene Muskelplasma reagiert auf empfindliches Lackmuspapier schwach alkalisch und bleibt bei Zimmertemperatur zunächst ganz klar. Bei Körpertemperatur wird die Reaktion bald sauer, und es tritt eine flockige Gerinnung ein.

Die Versuche wurden nun folgendermaßen angestellt: Hunde oder Katzen wurden getötet (s. u.), die Muskeln abpräpariert, durch eine Fleischhackmaschine grob zerkleinert und gemischt, und entweder allein oder zusammen mit dem Pankreas desselben Tieres in der Kosselschen Maschine zerschnitten und ausgepreßt. $\mathrm{Zu}$ dem erhaltenen Saft wurde Traubenzucker in bekannter Menge gesetzt, in einem 'Teil der Zuckergehalt nach Entfernung des Eiweißes bestimmt, der übrige Teil mit großen Mengen Toluol versetzt und bei Körpertemperatur stehen gelassen. Entweder setzte ich die Flaschen in den Brütschrank, oder ich versenkte sie in ein auf $37-38^{\circ}$ eingestelltes Wasserbad, und leitete einen lebhaften Luftstrom durch die Flaschen. Wie die Versuche 1, 2, 4, 9 und 10 zeigen, waren die Resultate dabei immer besser, als ohne Luftdurchleitung. Die bald auftretende saure Reaktion wurde durch wiederholten Zusatz von doppeltkohlensaurem Natron bekämpft. In einigen Versuchen setzte ich statt dessen $\mathrm{MgCO}_{3} \mathrm{zu}$ (Versuch 3, 9), doch schien dies zu stören. Nach einer bestimmten Zeit wurde das Eiweiß koaguliert und im Filtrat von neuem der Zucker bestimmt.

Die Koagulation erfolgte, wie ich früher ${ }^{2}$ ) beschrieben habe, durch Kochen unter Zusatz von Chlornatrium und Essigsäure; ich erhielt so immer ein klares, schnell filtrierendes Filtrat. In diesem titrierte ich den Zucker mit ammoniakalischer Kupferlösung nach Pavy. Ich habe schon mehrmals darauf hinge-

1) W. Kühne, Virchows Arch. 26, 222, 1863. - Protoplasma u. Kontraktilität, Leipzig, Engelmann, 1864.

2) 0. Cohnheim, Diese Zeitschr., Bd. XXXIII, S. 455, 1901. 
wiesen, ${ }^{1}$ ) daß die Pavysche Methode der Zuckerbestimmung sehr bequem ist und sehr genaue Resultate liefert. Die Angaben in Hupperts Harnanalyse, ${ }^{2}$ ) die Anwesenheit von Salzen und anderen Stoffen störten die Methode, ist unrichtig. Ich habe mich auch jetzt wieder durch eine größere Reihe von Kontrollversuchen überzeugt, daß ich im Filtrat des Muskelplasmas richtige Werte erhielt. Als Beispiel führe ich an: Muskeln und Pankreas einer Katze werden zerschnitten und ausgepreßt. Es resultieren $87 \mathrm{ccm}$, die mit Toluol versehen in den Brutschrank kommen und durch $\mathrm{NaHCO}_{3}$ alkalisch gehalten werden. Am nächsten Tage werden

a) $42 \mathrm{ccm}$ ohne Zusatz koaguliert und titriert. $61 \mathrm{mg}$ Dextrose, also in $20 \mathrm{ccm} 29 \mathrm{mg}$.

b) $20 \mathrm{ccm}$ wurden mit $250 \mathrm{mg}$ Dextrose versetzt, umgeschüttelt, koaguliert und titriert. $273 \mathrm{mg}$.

c) $20 \mathrm{ccm}$ mit $500 \mathrm{mg}$ Dextrose versetzt, umgeschüttelt, koaguliert und titriert. $520 \mathrm{mg}$.

Der gewöhnlichen Bestimmung nach Fehling haftet noch ein Übelstand an: Ammoniak und andere Körper halten Kupferoxydul in Lösung. Auch dies ist bei der Pavyschen Methode nicht der Fall. In dem angeführten Beispiel gab die $61 \mathrm{mg}$ Zucker enthaltende Lösung a) z. B. keine Reduktion mit Fehlingscher Lösung. Über die Störung durch Pepton s. u.

Ich gebe im folgenden nur die letzten Versuche wieder, bei denen die oben geschilderte Technik völlig ausgebildet war. Unter den früheren Versuchen hatte ich zwar eine Reihe positiver, daneben aber auch zahllose Fehlversuche, und sehe daher von der Zitierung der positiven ab. Da der Muskel selbst Zucker, auch andere reduzierende Körper enthält, so ist bei den meisten Versuchen der Zuckergehalt anfangs nicht unerheblich größer, als ihn der Zusatz allein bedingt.

1) 0. Cohnhe im, Zeitschr. f. Biol. 37, 129, 1898. - Diese Zeitschr., Bd. XXXIII, S. 25, 1901.

2) Neubauer u. Vogel, Analyse des Harns. 10. Aufl. von Huppert, S. $773,1898$. 


\section{Versuch 1:}

Katze. $90 \mathrm{~g}$ Muskeln ohne Pankreas ergeben $50 \mathrm{ccm}$ Preßsaft. Zugesetzt 0,75 g Dextrose.

\section{Sofort $765 \mathrm{mg}$}

Am nächsten Tage 764 ,

$350 \mathrm{~g}$ Muskeln derselben Katze + Pankreas geben $206 \mathrm{ccm}$. Zusatz 4,5 g Dextrose.

$127 \mathrm{ccm}$ (Luftdurchleitung) $=205 \mathrm{~g}$ Muskeln.

Vorher 2,083 g Zucker

Nachher 1,37 $\circ$,

$0,713 \mathrm{~g}$ umgewandelt $=3,5 \mathrm{~g}$ pro Kilogramm.

$30 \mathrm{ccm}$ (Brutschrank) $=50 \mathrm{~g}$ Muskeln.

Vorher $0,493 \mathrm{~g}$ Zucker

Nachher 0,375 , ,

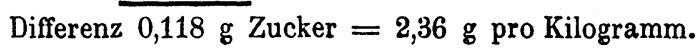

$30 \mathrm{ccm}+30 \mathrm{ccm}$ Serum (Brutschrank) $=50 \mathrm{~g}$ Muskeln.

Vorher $0,493 \mathrm{~g}$

Nachher 0,426 ,

Differenz $0,067 \mathrm{~g}$

\section{Versuch 2.}

Hund, 6 Tage nach Pankreasexstirpation. 275 g Muskeln ohne Pankreas ergeben $140 \mathrm{ccm}$. 0,5 g Dextrose. Luftdurchleitung.

$120 \mathrm{ccm}$. Vorher $0,852 \mathrm{~g}$ Zucker

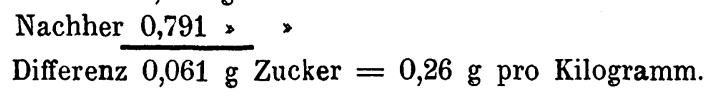

$350 \mathrm{~g}$ Muskeln desselben Hundes +1 Pankreas eines andern Hundes. $190 \mathrm{ccm}$. 4,0 g Dextrose.

$107 \mathrm{ccm}$ (=190 g Muskeln). Luftdurchleitung.

Vorher 2,493 g Zucker

Nachher 1,41 , ,

Differenz $1,08 \mathrm{~g}$ Zucker $=5,6 \mathrm{~g}$ pro Kilogramm.

$30 \mathrm{ccm}$ ( $=53 \mathrm{~g}$ Muskeln). Brutschrank.

Vorher $0,700 \mathrm{~g}$ Zucker

Nachher 0,520 , ,

Differenz $0,180 \mathrm{~g}$ Zucker $=1,3 \mathrm{~g}$ pro Kilogramm.

$30 \mathrm{ccm}+$ Blut (=53 g Muskeln). Brutschrank.

Vorher $0,700 \mathrm{~g}$ Zucker (?)

Nachher 0,606 , , 


\section{Versuch 3.}

Katze. Durch Äther getötet. $450 \mathrm{~g}$ Muskeln + Pankreas geben $214 \mathrm{ccm}$. Dazu $3 \mathrm{~g}$ Dextrose.

Die Hauptmasse mit Luftdurchleitung geht verloren.

$30 \mathrm{ccm}$ (= $59 \mathrm{~g}$ Muskeln). Brutschrank.

Vorher $0,464 \mathrm{~g}$ Zucker

Nachher 0,225, ,

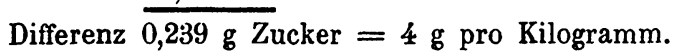

$30 \mathrm{ccm}+\mathrm{MgCO}_{3}(=59 \mathrm{~g}$ Muskeln). Brutschrank.

Vorher 0,464 g Zucker

Differenz $\frac{0,279>}{0,185 \mathrm{~g} \text { Zucker. }}$

\section{Versuch 4.}

Katze. 500 g Muskeln + Pankreas + $130 \mathrm{ccm}$ Ringersche Lösung geben $460 \mathrm{ccm}$. Zusatz 5,0 g Dextrose. Toluol.

Muskeln.

Je $30 \mathrm{ccm}$ werden koaguliert. Sie entsprechen ca. $31 \mathrm{~g}$

Vorher 0,564 g Zucker

Nach $31 / 2$ stündiger Luftdurchleitung 0,451, ,

, 19 ,

Brutschrank mit Toluol

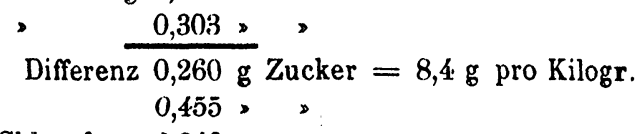

$>\quad>$ + Chloroform 0,342,

,, + Thymol 0,383,

\section{Versuch 5.}

Katze. $180 \mathrm{~g}$ Muskeln ohne Pankreas geben $106 \mathrm{ccm}$. $0,75 \mathrm{~g}$ Dextrose.

$88 \mathrm{ccm}(=147 \mathrm{~g}$ Muskeln). Luftdurchleitung. Vorher $7: 39 \mathrm{mg}$ Nachher 631 \&

Differenz $\overline{108 \mathrm{mg}}=0,73 \mathrm{~g}$ pro Kilogramm.

Das Pankreas derselben Katze mit gekochten Muskeln versetzt. Gibt $53 \mathrm{ccm}$.

Vorher 1,25 g Dextrose

Nachher 1,25 , , 


\section{Versuch 6.}

Hund, 3 Tage nach Pankreasexstirpation. $335 \mathrm{~g}$ Muskeln geben $180 \mathrm{ccm}$, wovon 150 verwendet werden. 1,0 g Dextrose zugesetzt.

$131 \mathrm{ccm}$ (Luftdurchleitung). Vorher $1,179 \mathrm{~g}$

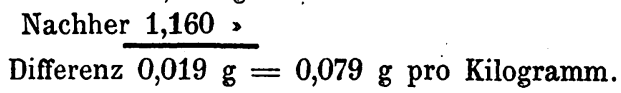

315 g Muskeln desselben Hundes + Pankreas. Gibt $150 \mathrm{ccm} .2,5 \mathrm{~g}$ Dextrose zugesetzt.

$139 \mathrm{ccm}$ enthalten vorher $2,526 \mathrm{~g}$ Zucker nachher $2,58,(?)$

S. u.

\section{Versuch 7.}

2 Hundepankreasdrüsen durch physiologische Kochsalzlösung angefroren, zerschnitten und ausgepreßt.

\section{Zugesetzt $0,75 \mathrm{~g}$ Dextrose \\ Erhalten 0,76 , ,}

Versuch 8.

1 Katzenpankreas wird mit den gehackten Muskeln derselben Katze gefroren, zerschnitten und gepreßt.

\section{Zugesetzt $0, \bar{j}$ g Dextrose \\ Erhalten 0,59, ,}

Es folgen einige Versuche, bei denen statt des Traubenzuckers Glykogen zugesetzt wurde, und außerdem bei 9 und 11 ein Stück Leber desselben Tieres, um das Glykogen vollständiger als durch die Dextrose des Pankreas zu verzuckern. Zur Glykogenbestimmung wurde das Eiweiß wie sonst koaguliert, sehr gut mit heißem Wasser ausgewaschen und das Filtrat mit Salz- oder Schwefelsäure von 1-2\% 1-2 Stunden gekocht, dann nach Pavy titriert. Zu Ende des Versuches wurde die vorhandene Reduktion dadurch nicht oder wenig vermehrt. Die Spaltung war also eine vollkommene gewesen.

Versuch 9 .

Hund, sehr fett, mit Struma behaftet. $620 \mathrm{~g}$ Muskeln, Pankreas und Leber, und $150 \mathrm{ccm}$ Ringersche Lösung geben 
$415 \mathrm{ccm}$ Flüssigkeit, wozu $4 \mathrm{~g}$ Glykogen in $150 \mathrm{~cm}$ Rieger sche Flüssigkeit gesetzt werden. In je $30 \mathrm{ccm}$ wurden die Bestim mungen ausgeführt, die vorher nach dem Kochen des Filtrate mit Säure $583 \mathrm{mg}$ Traubenzucker enthielten.

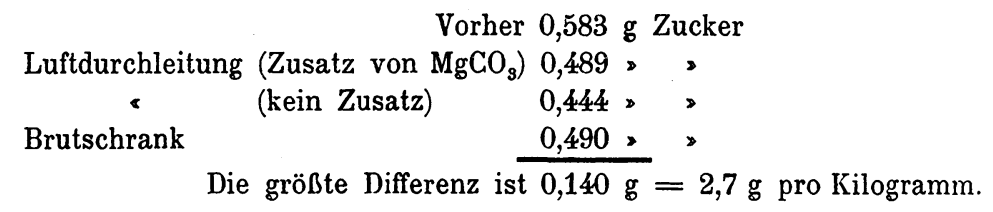

$$
\text { Versuch } 10 .
$$

Katze. 600 g Muskeln f-Pankreas und $120 \mathrm{ccm}$ Ringer sch Lösung geben $505 \mathrm{ccm}$, wozu $4 \mathrm{~g}$ Glykogen in $150 \mathrm{ccm}$ Ringer sche Lösung kommen.

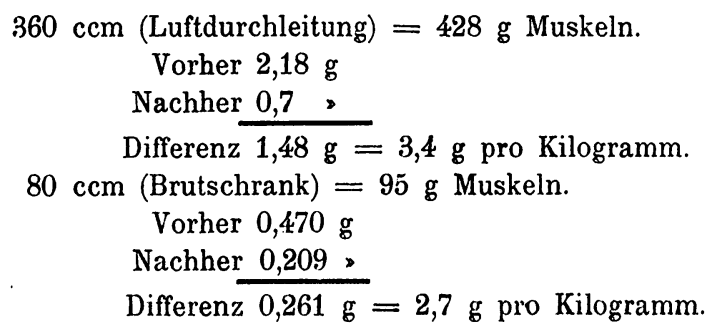

\section{Versuch 11.}

Katze. Muskeln, Pankreas, etwas Leber. Zusammeı $500 \mathrm{~g}+130 \mathrm{ccm}$ Ringersche Flüssigkeit geben $430 \mathrm{ccm}$. Zusatz von $6 \mathrm{~g}$ Glykogen in $100 \mathrm{ccm}$ Ring erscher Lösung. $\mathrm{Zl}$ der einen Hälfte wurde Serum, zur andern Ring ersche Lösun; gesetzt. Je $30 \mathrm{ccm}$ wurden untersucht
a) mit Serum.
Vorher $230 \mathrm{mg}$
Nachher 200 ,
Differenz $30 \mathrm{mg}$
b) mit Ring erscher Lösung. Vorher $260 \mathrm{mg}$
Differenz $135 \mathrm{mg}$

Bei den bekannten Schwierigkeiten jeder Glykogerbestimmung möchte ich auf den quantitativen Ausfall dieser Ver suche weniger Wert legen. 
Bei den folgenden Versuchen wurde kein Toluol zugesetzt. Bakterienwirkung war da.

\section{Versuch 12.}

Hund. $600 \mathrm{~g}$ Muskeln, Pankreas $+160 \mathrm{~cm}$ Ringerscher Lösung geben $468 \mathrm{ccm}$. Zusatz von 7,5 g Dextrose. $\mathrm{Zu}$ einer Hälfte Serum zugesetzt.
a) Ohne Zusatz.
Vorher $0,769 \mathrm{~g}$ Zucker
b) Mit Serum.

Vorher $0,769 \mathrm{~g}$ Zucker
Nach $61 / 2$ Stunden 0,625
$>21$,
Vorher 0,513,
Nach $61 / 2$ Stunden 0,544,
$>21>0,202$,

\section{Versuch 13.}

Hund. Muskeln, Pankreas $580 \mathrm{~g}+160 \mathrm{ccm}$ Ringerscher Lösung geben $415 \mathrm{ccm}$. Dazu $118 \mathrm{ccm}$ Serum des gleichen Tieres. $6,0 \mathrm{~g}$ Dextrose zugesetzt. Je $30 \mathrm{ccm}$ koaguliert.

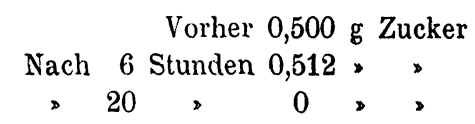

Versuch 14.

Hund. 605 g Muskeln + Pankreas + $280 \mathrm{ccm}$ Ring er scher Lösung geben $590 \mathrm{ccm}$. 7,5 g Dextrose. Ein Teil ohne Zusatz, ein Teil mit wenig Toluol.

a) Ohne Zusatz.

Vorher $0,363 \mathrm{~g}$

Nach 5 Stunden 0,340 ,

b) Mit etwas Toluol.

$$
\rightarrow 22>0 \text {, }
$$

Vorher 0,363 .

Nach 5 Stunden 0,355 ,

22 > 0 ,

Selbstverständlich habe ich mich durch besondere Versuche überzeugt, daß die in Betracht kommende alkalische Reaktion unter gleichen Versuchsbedingungen nicht zu einem Verlust von Traubenzucker führt.

Die Versuche beweisen, daß Muskeln und Pankreas zusammen Zucker zerstören, Pankreas allein dagegen garnicht $(5 \mathrm{~b}, 7,8)$ und Muskeln allein $(1 \mathrm{a}, 2 \mathrm{a}, 5 \mathrm{a}, 6 \mathrm{a})$ auch garnicht, 
oder nicht in nennenswertem Maße. Und diese Zuckerverbrennung ist groß genug, um mit den Verhältnissen im lebenden Körper verglichen werden zu können. Sie beträgt im Versuch 2 5,6 g pro Kilogramm Muskel. Rechnet man, daß ein erwachsener Mann $40 \mathrm{~kg}$ Muskeln besitzt, so würden von dem in den Muskeln vorhandenen Ferment über $200 \mathrm{~g}$ Dextrose oxydiert werden können, nach Versuch 4 sogar noch bedeutend mehr. Und diese Werte sind nur Minimalzahlen. Denn in den Muskeln ist ja in der Regel Glykogen enthalten, das im Laufe des Versuchs in reduzierende Kohlehydrate übergeht, sodaß der Zuckergehalt steigt, wie man dies z. B. in dem Fehlversuch $12 \mathrm{~b}$ sieht. Ich habe einigemal diesen Wert zu bestimmen versucht, indem ich wie in den Glykogenversuchen vor der Zuckerbestimmung das Filtrat mit Säure kochte. Doch möchte ich bei der Unsicherheit dieser Bestimmung und den kleinen Werten von einer Wiedergabe absehen.

Zunächst seien noch einige Besonderheiten besprochen. Wie schon erwähnt, zeigen die Versuche $1 b, 2 b, 4$ und 9 , daß die Zuckerzerstörung eine größere ist, wenn man einen Luftstrom durch die Lösung streichen läßt. Ob dies auf der besseren Mischung beruht, auf der Wegführung von Reaktionsprodukten oder auf spezifischer Sauerstoffwirkung, müssen weitere Versuche mit anderen Gasen entscheiden. In den Versuchen $1 \mathrm{~b}, 2 \mathrm{~b}, 11$ und 12 zeigt sich eine hemmende Wirkung von zugesetztem Blutserum desselben Tieres. Es scheint danach, daß das Blut wie auf das Trypsin, so auf das glykolytische Ferment einen antireaktiven Einfluß ausübt, vielleicht ein wirkliches Antiferment besitzt. Es würde so vermieden, daß der Traubenzucker im Blut verbrennt, wo er nur Wärme, aber keine Arbeit liefern kann. Ich habe infolgedessen in allen späteren Versuchen die Tiere möglichst blutfrei gemacht, indem ich sie aus der Carotis entblutete, und gleichzeitig Ringersche Lösung in die Vena jugularis externa einlaufen ließ. Von den angeführten ist nur in Versuch 3 diese vollständige Entblutung infolge vorzeitigen Todes der Katze unterblieben, er zeigt allerdings eine recht gute Zuckerzerstörung. Jedenfalls bedarf die Erscheinung genauerer Untersuchung. 
Endlich wird die Zuckerzerstörung durch Trypsin hintangehalten. Die Pankreasdrüsen enthalten in der Regel nur Zymogen. Am Ende des Versuches geben die enteiweißten Filtrate keine Millonsche, keine Biuretreaktion und keinen stärkeren Phosphorwolframsäureniederschlag, als Muskelextrakt schon vorher. Einmal bei einer Katze, mehrmals bei Hunden aber war das Bild ein anderes. Am nächsten Morgen war die Lösung nicht mehr rötlich, sondern infolge Zerstörung des Hämoglobins braun, die sonst vorhandenen dicken Myosingerinsel fehlten, das Filtrat nach der Eiweißkoagulation gab eine sehr starke Millonsche und Biuretreaktion. Wegen der Biuretreaktion ist dann eine genaue Bestimmung des Zuckers ganz unmöglich, und soweit ich sie auszuführen vermochte, ergab sie, daß keine Verminderung eingetreten war. Ich führe als Beispiel Versuch $6 \mathrm{~b}$ an. Sonst habe ich diese Versuche einfach ausgeschaltet. Bei der großen Mehrzahl habe ich keine Störung durch Trypsin bemerkt.

Die Hauptgefahr ist natürlich die Bakterienwirkung. Ich habe mich dagegen durch Anwendung großer Mengen Toluol geschützt, und Versuch 4 beweist, daß die Zuckerzersetzung hauptsächlich in den ersten Stunden vor sich geht: in $3^{1 / 2}$ Stunden wurden 113, in den folgenden $15^{1} / 2$ Stunden $148 \mathrm{mg}$ in je $30 \mathrm{ccm}$ zerlegt. Toluol stört die Fermentwirkung nicht. In Versuch 12, bei dem kein Toluol zugesetzt wurde, war die glykolytische Wirkung nicht größer. Das ist Ferment-, aber keine Bakterienwirkung. Derselbe Versuch beweist, daß auch Chloroform und Thymol in großen Mengen nicht stören. Setzt man freilich kein oder zu wenig Toluol hinzu, so unterliegt man groben Täuschungen. Versuche 12-14 zeigen, daß in dem vortrefflichen Nährboden - Sauerstoff, Kohlehydrate, Eiweiß, Salze im Überfluß - die Bakterien so stark wuchern, daß sie in 22 Stunden 6 und $7 \mathrm{~g}$ Zucker völlig verbrannten. Aber diese Verbrennung geht nicht in den ersten Stunden vor sich, sondern wird erst später lebhaft (Versuch 12-14), da die Bakterien natürlich Zeit brauchen, sich zu entwickeln.

Ehe ich die schädliche Wirkung des Blutes und gelegentlich des Flüssigkeitszusatzes kannte, schob ich die häufigen 
Mißerfolge auf eine Schädigung des Ferments durch das Toluol und habe mich mit allen erdenklichen Desinfizentien abgemüht, auch aseptisch zu arbeiten versucht. Das ist aber unmöglich. Obwohl ich mit sterilen Gefäßen und Apparaten hantierte, und obwohl die Buchnerpresse ein nahezu steriles Filtrat liefert, kommt es rettungslos zur Luftinfektion. Die Angaben von Stoklasa ${ }^{1}$ ) und Šimáček ${ }^{2}$ ) beruhen einfach auf diesem Fehler. Sie haben kein Desinfiziens zugesetzt und daher Bakterienwirkung erhalten. Toluol etc. hatten nicht das Ferment geschädigt, sondern die Bakterien ferngehalten, die dessen Wirkung vortäuschten. Šimáč $\mathrm{ek}^{\mathbf{3}}$ ) hat das ja unterdessen auch rückhaltlos zugegeben, und wenn er doch noch eine geringe Glykolyse retten will, so ist diese auch unrichtig. Denn die sicher antibakterielle Wirkung starker Zuckerlösungen bleibt noch erst zu beweisen. Daß ein Ferment erst am zweiten Tage wirkt und nicht sofort, spricht sehr dafür, daß auch hier Infektion durch Luftkeime die Glykolyse vorgetäuscht hat.

Kommt es zur bakteriellen Infektion, so wird die Flüssigkeit sehr stark sauer. Sonst ist das dagegen nur unbedeutend und nur im Anfange der Fall. Dann entspricht es der bekannten postmortalen Säurebildung im Muskel und hat auch statt, wenn kein Zucker zugegen ist und wenn keine Zuckerzerstörung stattfindet. Diese postmortale Säuerung ist ja auch sonst noch unaufgeklärt. ${ }^{4}$ ) Sie findet in der ersten Stunde statt. Nachher ändert sich in den aseptischen Versuchen die Reaktion nicht mehr. Ich habe durch Zusatz von $\mathrm{NaHCO}_{3}$ die anfänglich entstandene Säure stets möglichst genau zu neutralisieren gesucht. Jedes stärkere Sauer- oder Alkalischwerden schien die Zersetzung des Zuckers ungünstig zu beeinflussen, und die kleinen Differenzen mancher Parallelversuche (z. B. 4) schienen mir hierauf $\mathrm{zu}$ beruhen. Doch bedarf auch dies noch der Untersuchung.

1) J. Stoklasa u. F. Gzerny, B. B. 36, 622, 1903.

2) E. Šimáček, Zentralbl. f. Physiologie 17, 3, 1903.

3) Derselbe, ibid., 17, 209, 1903.

$\left.{ }^{4}\right)$ A. Heffter, Schmiedebergs Arch. f. experiment. Pathologie u. Pharmakol. 38, 447, 1897. 
Um den Traubenzucker im Körper zu verbrennen, bedarf es also des Zusammenwirkens zweier Organe, der Muskeln und des Pankreas. Da diese Verbrennung sich auBerhalb der Zellen in einer homogenen Lösung vollzieht, so ist sie die Wirkung eines Fermentes. Man kann den Vorgang in Analogie setzen entweder mit den von Ehrlich gefundenen Tatsachen, daß zur Lysinwirkung Komplement und Zwischenkörper nötig sind, oder man kann an $\mathrm{Pawlows}$ Enterokinase denken, die von der Darmschleimhaut sezerniert wird und das Trypsinogen des Pankreassaftes aktiviert. Da beide Vorgänge chemisch noch unbekannt sind, bedarf es physiologisch einstweilen keiner Entscheidung. Dagegen leuchtet die Zweckmäßigkeit der Anordnung ein. Die Zuckerverbrennung muß im Muskel erfolgen, da nur dort die aus ihr stammende Energie verwertet werden kann. Da aber der flüssige Muskelinhalt es (s. o. S. 338) schwer ermöglicht, das Enzym von dem Traubenzucker zu trennen, so wird es offenbar immer nur in dem Maße aktiviert, wie es erforderlich ist. Die Aktivierung wird durch einen Stoff bewirkt, den die innere Sekretion des Pankreas liefert.

Ich hoffe bald über die Isolierung der beiden Fermente und die Spaltungsprodukte, von denen ich bisher nur Kohlensäure nachgewiesen habe, berichten zu können. 